\title{
Ação coletiva e desenvolvimento sustentável
}

\section{Collective Action and Sustainable Development}

\author{
Ghislaine DUQUE* \\ Antônio Carlos Pires de MELLO** \\ Maria da Glória Batista de ARAÚJO***
}

\begin{abstract}
RESUMO
Este artigo pretende demonstrar a relação entre ação coletiva e desenvolvimento sustentável. Apos apresentar a região semiárida da Paraíba, onde se situa o caso estudado, descreve os problemas que afetam sua população: problemas ligados aos fatores edafo-climáticos da região e, mais ainda, aos fatores políticos, caracterizados pela dominação do clientelismo. Mostra como a ação coletiva teve início a partir do enfrentamento das necessidades sofridas pela população, quais foram os caminhos percorridos para encontrar soluções e viabilizá-las, aproveitando os saberes ancestrais em diálogo com o saber técnico, e como as comunidades participantes, libertando-se da dependência, ganharam autonomia e autoestima. Resultou desse processo a criação de uma organização, o "Coletivo", cuja contribuição foi decisiva para ampliar a ação coletiva, valorizando as experiências da base e fomentando sua divulgação, integrando finalmente as comunidades numa luta comum contra os problemas encontrados. As experiências do "Coletivo", bem como de outras entidades atuando nas várias regiões do semiárido, resultaram na criação de uma organização maior, a "Articulação no Semi-Árido" (ASA) que, partindo das experiências exitosas das comunidades, propôs e conseguiu que fossem adotadas pelo governo como políticas públicas. $\mathrm{O}$ artigo conclui que a sustentabilidade do desenvolvimento em curso decorre essencialmente do fato de que as soluções propostas não foram planejadas e impostas "de cima para baixo", mas foram baseadas em experiências da base.
\end{abstract}

Palavras-chave: ação coletiva; desenvolvimento sustentável; semiárido; agricultura familiar; comunidades rurais.

\begin{abstract}
This paper intends to show the connection between collective action and sustainable development. After presenting the semi-arid zone in Paraíba, wherein this case study is located, the problems which affect its population are outlined: problems linked to the soil and climatic issues in that region, and to other political factors, manifestly by the domination of political patronage, as well. It shows how the collective action has begun from coping with the necessities experienced by the population, the roads that have
\end{abstract}

\footnotetext{
" Doutora em Sócio-Economie du Développement (EHESS, França). Professora da Universidade Federal de Campina Grande (UFCG) e Professora visitante sênior da Universidade Federal do Vale do São Francisco (UNIVASF). E-mail: ghduque@uol.com.br

${ }^{* *}$ Mestre em Sociologia (UFPB). PATAC - Programa de Aplicação de Tecnologia Apropriada às Comunidades. E-mail: tunicopatac@yahoo.com.br

*** Especialista em Educação (UFPB). PATAC - Programa de Aplicação de Tecnologia Apropriada às Comunidades. E-mail: gloria@patac.org.br
} 
been taken to find out solutions and make them viable, taking advantage of the ancestral knowledge in harmony with technical knowledge, and how the participating communities releasing themselves from such dependence have gained autonomy and self-esteem. It has resulted from that process the creation of an organization, the "Collective", whose contribution has been conclusive to widen the collective action, enhancing the basic experiments and thus encouraging its release, and finally integrating the communities in a common struggle against the problems identified. Those experiences with the "Collective" and other groups operating in various regions of the semiarid zone of Brazil resulted in the formation of a larger organization: the "Articulation in the Semiarid" (ASA), which building on successful experiences of the communities proposed and managed that those were enforced by the Government as public policies. The paper concludes that the sustainability of the current development derives primarily from the fact that the solutions proposed have not been planned and imposed "from above", but grounded on experience at base.

Keywords: collective action; sustainable development, semi-arid; family farming; rural communities.

\section{Introdução}

Pretendemos demonstrar aqui, a partir de um estudo de caso, a relação entre ação coletiva e desenvolvimento sustentável. Apresentaremos a experiência do Coletivo Regional do Cariri, Curimataú e Seridó (Paraíba), que conseguiu, a nosso ver, um progresso sensível no sentido do desenvolvimento sustentável. Pretendemos verificar quais foram as condições e as metodologias praticadas para que tal resultado fosse possível. Queremos também identificar quais foram os principais obstáculos encontrados.

Inicialmente, definiremos rapidamente qual é nossa compreensão do conceito de "desenvolvimento" e indicaremos quais são, a nosso ver, as condições de sua sustentabilidade. Apresentaremos a seguir o contexto físico, social e político do caso estudado - a região semiárida da Paraíba - e mostraremos quais são os principais (e grandes) problemas que afetam sua população. Poderemos então descrever como esses problemas foram enfrentados e quais os caminhos percorridos, com seus sucessos e suas dificuldades, para encontrar soluções e viabilizá-las, graças à ação coletiva das comunidades participantes. Resultou desse processo a criação de uma organização - o "Coletivo" - cuja contribuição foi decisiva para um desenvolvimento realmente sustentável, levando inclusive ao engajamento do poder público. Finalmente concluiremos resumindo as lições da experiência.

\section{“Desenvolvimento" e "sustentabilidade"}

Quanto à definição do desenvolvimento, lembraremos apenas as diversas dimensões do mesmo que, hoje, são objetos de consenso: não apenas o aspecto econômico, mas ainda as dimensões ambientais e sociais e suas condições técnicas e políticas. O próprio caso que vamos analisar mostrará claramente a importância desses diversos aspectos.

Precisamos ainda explicitar o que entendemos por "sustentabilidade" do desenvolvimento. Sem descartar a definição bem conhecida do relatório Brundtland ("um desenvolvimento que responda às necessidades do presente sem comprometer a capacidade das gerações futuras em responderem às suas próprias necessidades"), acompanharemos o raciocínio de B. Hubert (2009), que nos parece mais concreto para o caso estudado. Para ele, dois aspectos são inerentes a essa noção: "o conceito de necessidade, e mais especificamente das necessidades essenciais dos mais desprovidos, e a ideia de limitação que o estado de nossas técnicas e de nossa organização social impõe sobre a capacidade do meio ambiente em responder às necessidades atuais e futuras".

A esse respeito, nosso caso parece exemplar, pois se trata do segmento mais pobre da sociedade (os agricultores familiares) na região talvez a mais problemática do Brasil (o Nordeste semiárido), problemática por suas condições naturais e por sua história, marcada pela concentração fundiária e pela dominação da oligarquia local.

Segundo B. Hubert (2009), esse desenvolvimento expressa "uma necessidade moral e política de arrancar a sociedade a seu estado", o que supõe "escolhas intencionais e projetos que precisam ter sua emergência facilitada na ação coletiva, e trajetórias que precisa acompanhar [...] nas suas dimensões ecológicas, técnicas, econômicas e sociais".

O notável no caso estudado é que é justamente a necessidade que tornou essas comunidades rurais abertas às propostas que lhes foram apresentadas: num primeiro 
tempo, propostas técnicas que souberam apelar para a parceria dos camponeses, aproveitando os saberes ancestrais em diálogo com o saber técnico. Depois, foi o fato de que as experiências técnicas, objetos de intercâmbios entre os agricultores e a seguir entre as comunidades, provocaram a necessidade de uma organização, seja para trocar saberes, assegurar a gestão dos recursos, discutir os problemas encontrados ou elaborar estratégias comuns.

Mas, antes de entrar na análise do caso, precisamos apresentar o contexto regional, que demonstra as carências de sua população.

\section{O contexto regional: o Nordeste semiárido}

Existem vários semiáridos pelo planeta. Entretanto nenhum deles tem a pluviosidade do brasileiro, nem sua extensão nem sua densidade populacional. Também em nenhum deles, as condições de vida são tão precárias como aqui. Evidentemente, não é um problema da natureza, é uma questão política, social e cultural. (MALVEZI, 2006)

Esta citação caracteriza bem as contradições do semiárido nordestino, ao mesmo tempo em que orienta a reflexão para as causas de seus problemas.

O semiárido brasileiro tem uma extensão de uns $900.000 \mathrm{~km}^{2}$. Abrange $70 \%$ do Nordeste e $63 \%$ de sua população. Nele residem uns 28 milhões de pessoas, sendo quase a metade na área rural. É no semiárido que se encontra o maior número de estabelecimentos agrícolas familiares do Brasil: cerca de dois milhões. Correspondem a $42 \%$ do número total de unidades agrícolas do país, mas ocupam apenas 4,2\% de sua área agrícola (IBGE, Censo agropecuário 1996).

Quando se fala no "semiárido", imediatamente é a seca que é evocada. Mas o que é a seca? Não é a falta de chuva, pois não chove pouco - a média anual de chuva varia de 300 a $800 \mathrm{~mm}$, segundo as regiões. Os problemas são a concentração das chuvas num "inverno" reduzido a uns três ou quatro meses por ano e sua irregularidade, seja ao longo da própria estação chuvosa, seja de um ano para outro. Mais importante ainda é o déficit hídrico causado pelo calor, pois se $800 \mathrm{~mm}$ de chuva em clima frio constituem uma boa média, em nosso clima tropical as perdas por evaporação são até três vezes maiores do que o volume de água trazido pelas chuvas. Daí porque os grandes açudes que favorecem a evaporação constituem uma péssima solução para o problema da "falta de água". Como disse um dia o escritor Ariano Suassuna (NOVAES, 2006), "ter no semiárido um departamento de obras contra as secas equivale a ter na Sibéria um departamento de obras contra a neve".

Outra característica do semiárido é seu subsolo, constituído em $70 \%$ por rochas cristalinas, o que torna a água do lençol freático facilmente salobra, como também favorece a salinização das terras em caso de irrigação mal controlada. Em cima desse subsolo rochoso, a camada de solos é bastante rasa, impedindo a penetração de raízes fundas, que poderiam sustentar árvores vigorosas. Daí porque a vegetação do semiárido se caracteriza principalmente por arbustos ou árvores de pequeno porte; as árvores mais altas refugiam-se nos baixios, onde a terra trazida pela erosão se acumulou. As folhas das árvores são geralmente pequenas, resumindo-se a espinhos no caso das cactáceas, o que constitui uma adaptação natural de resistência à evapotranspiração. A consequência é que a cobertura vegetal, constituída pelas folhas mortas caídas no chão, é fraca, o que não contribui para renovar o solo.

Mas, apesar de todas essas limitações, a flora e a fauna do semiárido são extremamente diversificadas, lá onde a natureza foi respeitada. A cobertura vegetal é chamada de "caatinga" (mata branca), pois, na estação seca, os ramos parecem brancos e acinzentados, como se fossem mortos. Mas a caatinga oferece um espetáculo primoroso quando volta a ficar verde e florida com as primeiras chuvas. Vale frisar que o bioma caatinga só existe no Brasil e abriga uma enorme diversidade de animais e de plantas, com as mais diversas utilidades: plantas medicinais, forragem para os animais, estacas para as cercas, madeira para as casas e, infelizmente, lenha para fazer carvão. Infelizmente, pois a fabricação de carvão como alternativa de renda provoca o desmatamento, uma das causas da desertificação. A camada superior do solo descoberta é arrastada pelo vento e pelas chuvas em pouco tempo (mas leva séculos para se reconstituir).

A desertificação é, portanto, estreitamente vinculada ao desmatamento e à perda da biodiversidade, a qual é favorecida pelos "pacotes" da revolução verde, difundindo as monoculturas. Estas exigem o uso intensivo de insumos químicos, que poluem o meio ambiente, e uma maquinaria pesada, que compacta os solos. Citemos ainda a irrigação em grande escala, mal controlada, que provoca a salinização dos solos (ver COHEN; DUQUE, 2001).

Finalmente, a causa mais fundamental da desertificação talvez seja a concentração fundiária que resulta na 
oposição contrastada entre latifúndios e minifúndios: os latifúndios obedecem, na sua maioria, às normas da "revolução verde", destruidora da natureza. Por outro lado, a falta de reforma agrária e a pressão do agronegócio impedem o acesso à terra para as novas gerações. Os pequenos produtores, pressionados pelas necessidades da sobrevivência, são levados a praticar o uso excessivamente intensivo de suas parcelas: abandono da prática do "pousio" (áreas deixadas em repouso durante um ou vários anos para deixar o solo se recompor) e carga excessiva de cabeças de gado em áreas limitadas. ${ }^{1}$

Finalmente, quando a terra se torna totalmente estéril, o agricultor abandona o campo, migra. Assim, a desertificação não é apenas um problema ambiental; o campo também se torna um deserto do ponto de vista populacional e cultural, pois é uma cultura que está morrendo.

Do ponto de vista social e político, as heranças da história pesam fortemente. O domínio dos "coronéis" 2 ainda é uma realidade, baseada na fome e na sede das populações carentes. Não são raros os políticos que distribuem água dos caminhões-pipa ou dão o transporte para o hospital em troca de submissão e votos. Esta estratégia de sobrevivência dos pobres mediante "favores" do poder local, seja ele representado pelo grande proprietário, pelo "chefe" político, pelo poder municipal ou estadual, continua imperando, dando continuidade ao "poder dos donos" (BURSZTYN, 2008). Mesmo os programas ditos "participativos" não puseram fim a essa situação. O melhor exemplo é o dos diversos conselhos municipais: não raramente, o prefeito nomeia seus membros e estes assinam documentos preparados por "especialistas", obedecendo às orientações do poder local. Isto significa dizer que nesses conselhos os representantes populares não defendem os interesses da população, mas referendam e legitimam a imposição de interesses alheios.

Essa "cultura da subalternidade" talvez seja o obstáculo mais forte para a inclusão social na região, pois manteve no poder até hoje uma classe política cujo interesse é manter a população na situação de dependência e não contribuir para a solução de seus problemas. Ora, a exclusão social gera pobreza e falta de informação, duas características do subdesenvolvimento. É essa situação de dependência e ignorância, grande responsável pela pobreza, que a ação coletiva enfrentou na região. ${ }^{3}$

\section{A origem da ação coletiva: as necessidades sentidas}

Resumiremos o caminho percorrido dizendo que se partiu das necessidades sentidas da forma mais premente pelas famílias e que se procuraram soluções para aliviá-las. Poderíamos pensar que as causas dos principais problemas identificados no capítulo acima seriam a falta de conhecimentos, a dependência política etc. De fato, esses eram problemas graves, mas as famílias talvez não tivessem consciência de sua importância. O que elas sentiam, o que mais provocava seu sofrimento, era a questão da água. As mulheres perdiam várias horas todos os dias para ir apanhar água poluída nos barreiros, carregando baldes pesados na cabeça. As crianças sofriam de diarreia.

A ação começou pela reflexão sobre esse problema. Discutiram-se soluções. Descobriu-se um tipo de cisterna "bem em conta" - redonda e semienterrada, feita de placas de cimento - e que podia ser construída pelas próprias famílias, após treinamento. Uma cisterna desse tipo recolhe a água de chuva caindo no telhado, armazenando 16.000 litros, o que permite a uma família de cinco pessoas dispor de água para beber e cozinhar durante uns sete meses, isto é, entre duas estações chuvosas. Mas como comprar o material? $\mathrm{Na}$ comunidade mais carente, mais distante de qualquer fonte de água, havia perto de cem famílias e os recursos conseguidos pelo PATAC ${ }^{4}$ (a ONG que apoiava as comunidades do município) só cobriam os custos com o material para cinco cisternas.

Foi quando se pensou na criação de um "Fundo Rotativo Solidário" (FRS), um tipo de crédito que não tem nada em comum com o empréstimo bancário. O princípio é o da solidariedade. Importa que cada família possa dar sua contribuição financeira e que o ritmo das "prestações" seja decidido em conjunto com a Associação da comunidade, obedecendo às condições econômicas das famílias. O retorno pode demorar bastante tempo, até que a quantia

\footnotetext{
${ }^{1}$ As divisões por herança reduziram drasticamente o tamanho das propriedades; estabelecimentos de mais de 100 hectares na geração dos avós se transformaram em minifúndios para os netos.

${ }^{2}$ Ver alguns clássicos, como FAORO, 1979; LEAL, 1975; PANG, 1979; como também SÁ, 1974, BURSTYN, 2008.

${ }^{3}$ Nossa reflexão se baseia no acompanhamento dessa experiência desde o início dos anos 1990 e de uma pesquisa realizada em 2003, utilizando entrevistas e reuniões nas diversas comunidades da região.

${ }^{4}$ Programa de Aplicação de Tecnologias Adaptadas às Comunidades.
} 
devolvida permita formar um novo Fundo para um novo grupo de famílias. Pode-se alegar que o ritmo das construções é lento, mas a comunidade não estava sofrendo há décadas e décadas sem solução?

Na gestão do FRS, as dificuldades não faltam. Certas famílias não podem assumir compromisso financeiro suficiente, embora sejam as mais necessitadas. O caso é discutido na Associação e soluções são propostas. Por exemplo, serviços prestados e remunerados. Ou ainda empréstimo de uma cabra, a dívida sendo paga com a venda dos filhotes e o animal devolvido ulteriormente. ${ }^{5} \mathrm{O}$ importante é o princípio da solidariedade e da decisão comunitária. Vale acrescentar que essa boa vontade solidária é facilitada pelo fato de que quase todas as comunidades rurais da região são constituídas por uma mesma parentela, descendente de um mesmo avô ou bisavô. ${ }^{6}$

\section{A institucionalização da ação coletiva}

Desde 1980, comunidades rurais do município de Soledade-PB (situado na fronteira entre as três microrregiões do Cariri, Seridó e Curimataú) tinham começado a se mobilizar, com o apoio do Sindicato dos Trabalhadores Rurais, da Igreja católica e de ONGs com atuação na região em torno de várias atividades: grupos de evangelização, "mutirões" (trabalhos comunitários), estocagem de sementes (os "bancos de sementes comunitários"). A gestão dos Fundos Rotativos Solidários foi a atividade que exigiu uma organização mais ampla e consolidada, abrangendo várias comunidades e, com o tempo, vários municípios. A experiência tinha iniciado na comunidade de Caiçara, município de Soledade, em 1993, integrando a seguir os municípios vizinhos, até atingir municípios das três microrregiões.

Inicialmente, o repasse dos recursos para um novo grupo de famílias, da mesma ou de outra comunidade, era decidido por uma organização criada para esse fim: o "Coletivo de Educação Solidária de Soledade", que reunia representantes das diversas comunidades. Foi aí que a ação coletiva começou a se institucionalizar. Como várias comunidades se situavam na fronteira entre Soledade e municípios vizinhos, o Coletivo passou a se chamar, em
1998, "Coletivo de Soledade e Entorno". Ampliando-se a ação, passou a abranger umas trezentas comunidades de dez municípios e ganhou, em 2006, o título de "Coletivo Regional do Cariri, Seridó e Curimataú".

Os FRSs talvez tenham constituído o instrumento mais forte para dar o "pontapé inicial": proporcionar às comunidades a oportunidade de fazer a aprendizagem da gestão coletiva de recursos - discutir os prazos de pagamento, decidir quem vai comprar o material, negociar os preços, prestar contas. Inicialmente, era a organização mediadora que assumia essa gestão. Aos poucos ela foi se retirando, repassando a responsabilidade para as Associações de cada comunidade. Essa lenta aprendizagem da tomada de decisões de forma democrática foi um passo importante para a organização da comunidade e o exercício da cidadania. As famílias foram descobrindo sua capacidade de se autoadministrar, ganhando autonomia e autoconfiança, sem depender de "favores". Tornaram-se cidadãos capazes de conduzir seu próprio destino. Vale frisar que essa nova autonomia não agradava aos políticos locais, que perguntavam: "Quem lhe deu essa cisterna?" E o produtor respondia, orgulhoso e batendo no próprio peito: "Ninguém me deu, eu paguei!"

A organização permitiu avançar na identificação e na discussão dos problemas. Soluções foram experimentadas: novas formas de captar água, desta vez para dessedentar os animais e aguar roçados e hortas ${ }^{7}$; os princípios do manejo agroecológico foram divulgados, os sistemas de produção

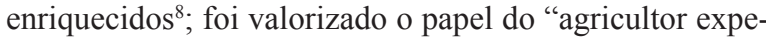
rimentador" e foram organizadas visitas de intercâmbio. Os representantes do Coletivo começaram a participar dos diversos Conselhos Municipais, onde defendem com autonomia os interesses da agricultura familiar da região.

Em 2006, a partir da necessidade de melhor organizar o funcionamento do Coletivo, foram identificados temas mobilizadores, sendo criadas três Comissões Temáticas: Comissão Água; Comissão Criação Animal; e Comissão Sementes, Plantas e Frutas. Cada Comissão realiza pelo menos uma reunião por mês, mobilizando mensalmente aproximadamente 100 lideranças dos dez municípios. São espaços estratégicos de diálogo entre agricultores(as), lideranças e técnicos(as), que têm proporcionado momentos de formação técnica e sócio-organizativa, bem como oportunidades de planejamento, avaliação e monitoramento das

\footnotetext{
${ }^{5}$ Esses exemplos foram identificados na pesquisa de 2003.

${ }^{6}$ As famílias que integraram a comunidade ulteriormente criaram laços por casamento ou compadrio.

${ }^{7}$ Cisternas calçadão, tanques de pedra, barragens subterrâneas etc.

${ }^{8}$ Armazenamento de forragem, cultivo de plantas medicinais etc.
} 
ações. Reuniões itinerantes ${ }^{9}$ se multiplicam por diversas comunidades da região e desembocam em eventos regionais estratégicos que fortalecem pontos de vistas críticos comuns acerca de temáticas como: transgênicos, agrotóxicos, transposição das águas do Rio São Francisco, sustentabilidade dos sistemas de criação animal etc.

Também ocorrem eventos semestrais de avaliação e planejamento, onde são construídas estratégias para aperfeiçoar os processos de formação, assim como são tiradas orientações para influenciar políticas públicas governamentais. Por exemplo, citamos a experiência da Comissão Sementes, Plantas e Frutas, que vivenciou uma metodologia continuada de formação que priorizou a discussão dos transgênicos na "Festa Regional da Semente da Paixão" (ou semente nativa), refletindo esta temática nas comunidades antes e depois desse evento regional.

Nos últimos anos, a partir da discussão dos problemas ligados à comercialização, foi criada a "Bodega Agroecológica", situada num local estratégico no centro de Soledade, que recebe e redistribui os produtos das comunidades, in $n a-$ tura (verduras e frutas) ou beneficiados (doces, bolos, mel). A "Bodega" se articulou com o Programa de Aquisição de Alimentos do Programa "Fome Zero", do Governo Federal, para repassar parte dos produtos da agricultura familiar para atender segmentos sociais que vivem em situação de risco (crianças e idosos) e que são acompanhados pelas pastorais sociais da Igreja católica. Também vendem produtos ao Programa Nacional de Alimentação Escolar. Finalmente, a "Bodega" é muito mais do que um simples ponto de comercialização de produtos da agricultura familiar: é um espaço de circulação e troca de conhecimentos.

O crescimento e a maior complexidade das ações do Coletivo demandaram a organização de uma Coordenação Regional composta por dois representantes de cada comissão temática. Esta Coordenação (integrando mulheres e jovens) se reúne quinzenalmente e tem o papel de coordenar e articular as ações promovidas pelo Coletivo, assim como representá-lo.

\section{Ação coletiva em nível interestadual e políticas públicas}

A rede regional do Coletivo entrou em diálogo com uma rede mais ampla: a Articulação do Semi-Árido Parai- bano (ASA/PB), ela própria integrada na mesma articulação em nível nacional (ASA/Brasil). Participando dessa dinâmica, o Coletivo Regional ampliou as possibilidades de informações mútuas, as trocas de saberes, a prática do diagnóstico comunitário, a sistematização dos conhecimentos, o aprendizado dos princípios da agroecologia e sua aplicação; participa assim da elaboração de referências (os experimentos dos agricultores) que são propostas às autoridades governamentais para que estas as adotem como políticas públicas, democráticas, adaptadas à região.

$\mathrm{O}$ projeto mais conhecido financiado como política pública, porém administrado pela ASA em cada Estado e em cada região, é o programa de cisternas ("Programa de Formação e Mobilização para a Convivência com o Semiárido: Um Milhão de Cisternas Rurais" - P1MC). Como o nome indica, esse programa visa, muito mais que construções, à formação e à organização das comunidades. O fato de que esse programa foi construído com base em experiências bem sucedidas foi fundamental para assegurar sua aceitação pelas autoridades governamentais e seu sucesso. O sucesso dessa parceria é importante para assegurar a continuidade da ação coletiva. É o Coletivo Regional que assumiu a gestão do P1MC na região.

Outro programa administrado pela ASA e assumido financeiramente pelo governo federal é o P 1+2: "Uma terra e duas águas". A discussão da reforma agrária e o manejo da terra preservando a biodiversidade de um lado e, por outro, a captação da água de chuva para duas finalidades: para beber e cozinhar (as cisternas do P1MC) e para produzir.

Outra ação bem sucedida, realizada especialmente no Estado da Paraíba, foi a luta pelo reconhecimento das sementes nativas. Essas sementes ("da Paixão", como são apelidadas na região) apresentam uma grande diversidade: algumas são mais precoces, outras mais produtivas, outras ainda mais resistentes aos predadores. Os produtores gostam de plantar "de tudo um pouco", para se prevenir contra qualquer evento. Antes, em caso de seca prolongada, quando as reservas das comunidades estavam esgotadas, a CONAB costumava distribuir sementes industriais, colocando em perigo a biodiversidade local. Após uma longa luta, a ação coletiva conseguiu com que a CONAB passasse a comprar essas sementes nativas (anteriormente desprezadas) para constituir reservas e abastecer os Bancos de Sementes Comunitários em caso de seca prolongada, o que foi uma vitória política, que reforçou a autoestima dos agricultores.

\footnotetext{
${ }^{9}$ As reuniões itinerantes mensais das comissões temáticas ocorrem nas comunidades onde, além de planejar e monitorar as ações desenvolvidas, acontecem visitas de campo às experiências comunitárias.
} 
O Coletivo participa ainda da formulação e da gestão de propostas no quadro do Fórum Territorial de Desenvolvimento Sustentável do Cariri Oriental, ligado à Secretaria de Desenvolvimento Territorial (SDT) do MDA, e está participando da criação do mesmo Fórum no Seridó. A título de exemplo, no Cariri foram conseguidas unidades móveis de máquinas forrageiras e de bombas de água. Graças à máquina forrageira, uma única comunidade de Soledade já estocou 100 toneladas de forragem. O Coletivo também está empenhado nos esforços para uma melhor gestão desses equipamentos, não só nos municípios onde atua, mas ainda em todo o território.

Esses exemplos mostram o sentido das respostas às perguntas que colocávamos inicialmente: se a ação coletiva contribui para libertar as famílias da submissão às forças políticas e econômicas dominantes, para enfrentar os problemas ambientais, para lutar contra a pobreza, para colaborar, finalmente, para um desenvolvimento que seja sustentável.

\section{Conclusões}

Qual é a originalidade desta experiência? Em primeiro lugar, não é o Estado que planejou e impôs suas políticas centralizadas, mas a base, organizada em "Coletivo", que experimentou e propôs políticas descentralizadas e adaptadas às situações locais e que os órgãos governamentais tiveram a sabedoria de adotar. Esta é, a nosso ver, uma condição essencial para assegurar a sustentabilidade do desenvolvimento que se inicia.

No caso estudado, trata-se de uma rede na escala microrregional (o Coletivo), partindo da base e formando com outras redes semelhantes uma articulação nacional, resultando na criação de políticas públicas. Essa articulação também é original:

- parte da base: famílias agricultoras reunidas nas organizações mais diversas: associações comunitárias, paróquias, sindicatos etc. Nada é imposto: nem um tipo de organização, nem normas de funcionamento;

- as demais redes semelhantes são articuladas nacionalmente. Sua força parte de sua capacidade de trocar experiências em todos os níveis, criando assim e divulgando propostas baseadas nos seus saberes e nas suas práticas;

- essas experiências se tornam então referências, que serão propostas e adotadas como políticas públicas;

- essas políticas públicas se tornam então realmente adaptadas às condições locais, uma vez que nasceram das experiências da base - uma condição essencial para sua sustentabilidade - e às capacidades de gestão dos atores.

Em que esta experiência - que abrange (vale lembrar) toda a região semiárida do Nordeste brasileiro, ou seja, em torno de $900.000 \mathrm{~km}^{2}$ - oferece uma mudança radical de perspectiva, sobretudo se comparada com a situação de uns 10 ou 15 anos atrás?

Além do fato de que as propostas não são pensadas para os agricultores por um órgão superior de planejamento, mas que elas partem das experiências e do saber da base, elas não são divulgadas por agentes técnicos, mas circulam entre agricultores, por mecanismos como visitas entre famílias ou entre comunidades, por boletins elaborados a partir de histórias de vida contadas pelas famílias, de encontros onde cada qual traz suas sementes, seus produtos, seu "saber-fazer".

Portanto, o papel dos agentes técnicos ou dos mediadores externos não é mais de levar um saber, mas de entender e apoiar as experiências da base. Vai então se estabelecer um diálogo entre práticas populares e saber técnico ou científico: quando os mediadores ou agentes técnicos descobrem e interpretam cientificamente os mecanismos que explicam a adaptação das práticas aos ecossistemas locais, eles passam a entender as lógicas sociais e podem justificar eventuais sugestões de melhorias.

Finalmente, quais seriam as perspectivas abertas para uma pesquisa futura? Precisará provavelmente analisar e propor soluções às dificuldades que esse processo gera, notadamente as novas relações que se estabelecem entre os atores coletivos, na base, e os órgãos do Estado.

A dificuldade principal, tanto para o Estado quanto para as organizações coletivas, é harmonizar dois níveis muito distintos de objetivos: os objetivos quantitativos de obras a serem construídas (quantas cisternas ou quanta produção, em quanto tempo), priorizadas pelo Estado, e os objetivos qualitativos dos movimentos sociais: um processo pedagógico que leva tempo, pois supõe uma mobilização popular, uma formação na base, não apenas para aprender as técnicas (de construção, de gestão agroecológica), mas ainda para entender o porquê do tratamento higiênico da água e dos alimentos, os princípios da segurança alimentar e, mais ainda, para diagnosticar as prioridades, praticar a negociação e a conciliação para chegar a decisões tomadas 
democraticamente. A grande tentação do Estado é impor ritmos que não tomem em consideração os objetivos pedagógicos, priorizando sempre os resultados estatísticos. E a tentação das comunidades, na base, é perder o ritmo... É neste ponto que uma primeira dificuldade de diálogo acontece. Finalmente, é o processo democrático que está em jogo.

Outra dificuldade reside na necessidade de adaptar normas que foram elaboradas para grandes obras, como a construção de estradas e de barragens, para pequenos projetos realizados em locais isolados por famílias dispersas. Não resta dúvida que normas têm que ser respeitadas, que a gestão dos recursos deve ser transparente, que uma fiscalização é normal. De fato, essas normas podem ser adaptadas, mas nenhuma "autoridade" dá orientação. A título de exemplo, são exigidas notas fiscais para refeições preparadas na oportunidade de um encontro, quando essas refeições são preparadas pelas mulheres da comunidade com os produtos de suas hortas. Ora, o ICMS (Imposto

\section{Referências}

BURSZTYN, Marcel. O poder dos donos: planejamento e clientelismo no Nordeste. 3. ed. revista e ampliada. Rio de Janeiro: Garamond; Fortaleza: BNB, 2008.

COHEN, Marianne; DUQUE, Ghislaine. Les deux visages $d u$ Sertão. Stratégies paysannes face aux sécheresses. Paris, IRD, 2001, $388 \mathrm{p}$.

FAORO, Raymundo. Os donos do poder: formação do patronato político brasileiro. 5. ed. Porto Alegre: Globo, 1979.

GUANZIROLI, C. E. (Coord.). Perfil da agricultura familiar no Brasil: dossiê estatístico. Projeto FAO/INCRA: UFT/ BRA/036, agosto de 1996.

HUBERT, Bernard. Entre Villes et Nature. Conferência no Seminário DESENVOLVIMENTO SUSTENTÁVEL E TERRITÓRIOS RURAIS (texto dat.). Campina Grande, setembro de 2009. sobre Circulação de Mercadorias e Prestação de Serviços) pode ser recolhido por meio de notas avulsas emitidas pela Secretaria de Estado da Receita (Coletoria Estadual). Quando uma estudante de Direito pertencente a uma das ONGs trabalhando na região descobriu o "segredo", ela o divulgou por intermédio das redes. A organização em rede tem condições de socializar as informações.

Finalmente seria necessário valorizar o controle social. Este é preconizado enfaticamente nas propostas de políticas públicas "participativas", mas de fato não é organizado. Precisaria, por exemplo, se dar maior publicidade aos objetivos e ao funcionamento das diversas políticas públicas, organizar encontros de avaliação das mesmas etc.

Para que uma parceria realmente eficaz e democrática entre ação coletiva e órgãos do Estado possa contribuir para o desenvolvimento sustentável importa, portanto, aprofundar a reflexão sobre as condições para que a ação coletiva possa se exercer com total eficiência.

IBGE: Censo agropecuário 1996. Disponível em: <http:// www.ibge.gov.br/home/estatistica/economia/agropecuaria/ censoagro/2006/default.shtm>. Acesso em: janeiro de 2008.

LEAL, Victor Nunes. Coronelismo, enxada e voto: o município e o regime representativo no Brasil. 2. ed. São Paulo: Alfa-Omega, 1975.

MALVEZZI, Roberto. O que é o semiárido brasileiro. In: Lista Asabranca, jun. 2006.

NOVAES, W. Uma nova visão do semiárido. O Estado de São Paulo, 23.06.2006.

PANG, Eul-Soo. Coronelismo e oligarquias (1889-1943). Rio de Janeiro: Civilização Brasileira, 1979. 269 p.

SÁ, M. Auxiliadora Ferraz de. Dos velhos aos novos coronéis. Recife: PIMES, 1974.

Recebido em setembro de 2011. Aceito em outubro de 2011. Publicado em junho de 2012. 